\title{
Anti-inflammatory effects of a Chinese herbal tea, Shangqingyin, in mice and rats
}

\author{
Long-Fang Tu' ${ }^{1,2 \#}$, Si-Rui Zhu ${ }^{1,2 *}$, Yi-Fei Zhong, ${ }^{1,2}$ Zi-Jian He ${ }^{1,2}$, Yong-Chang Chen ${ }^{1,2}$, Xiao-Jun Li ${ }^{1}$, Yi-Fang Li ${ }^{1,2 *}$ and Rong-Rong He ${ }^{1,2 *}$ \\ 1Anti-Stress and Health Research Center, College of Pharmacy, Jinan University, Guangzhou 510632, China \\ 2Institute of Traditional Chinese Medicine and Natural Products, Jinan University, Guangzhou 510632, China \\ \#These authors contributed equally to this work
}

\begin{abstract}
Shangqingyin (SQY), made from Fructus Chebulae, Frangipani, Reed Rhizome, Mesona, Patchouli, Liquorice, has been a famous herbal tea in Lingnan area in China since Tang dynasty. It is believed to be beneficial for human health, although experimental data are scarce until now. In the present study, we demonstrated that oral administration of SQY herbal tea significantly decreased the weights of granuloma in rats induced by cotton pellet, mitigated the paw edema induced by dextran in rats and alleviated the ear edema induced by dimethylbenzene in mice. These results indicated a potential anti-inflammatory effect of SQY, which preliminarily provide a scientific basis for its beneficial effects.
\end{abstract}

\section{Introduction}

Inflammation is the normal consequence of physiological and immune response to tissue injury induced by various stimuli, such as trauma, infection and toxic chemicals agents [1,2]. It plays a critical role on tumor development, cardiovascular disease, diabetes, Parkinson's disease, et al. Therefore, it's of great value to look for antiinflammation drugs. In Tang dynasty of China, people in Lingnan area in China often drank myrobalan soup to keep healthy. It was prepared by decocting fresh myrobalan (Fructus Chebulae) with Liquorice, tasting slightly sweet. In Ayurveda, Fructus Chebulae was commonly used as cardiotonic, digestive, diuretic, antitussive, antidiabetic and laxative [3,4]. Meanwhile, Fructus Chebulae was previously reported to have anticancer [5], antioxidant [6,7], anti-hyperglycemic [8], antimutagenic [9], anti-ulcer [10], hepatoprotective [11], and cardioprotective activities [12]. As time goes by, people combined Fructus Chebulae with some other traditional Chinese medicine, such as Frangipani, Reed Rhizome, Mesona, Patchouli, Liquorice, to make a herbal tea named SQY. In the present study, we investigated the anti-inflammatory effects of SQY herbal tea by employing three inflammation models including cotton pellet induced rat granuloma, dextran-induced rat paw edema and dimethylbenzene-induced ear edema.

\section{Materials and methods}

\section{Drugs and major reagents}

SQY (total net weight: $4.526 \mathrm{~kg}$ ) was provided by Xiangxue Pharmaceutical Co., Ltd. (Guangzhou, China). Dexamethasone sodium phosphate injection (DXM) was also used (batch no: 51504092) was bought from Tianjin King Group HuBeiTianYao Pharmaceutical Co., Ltd. (Tianjin, China).

\section{Animals}

SPF SD rats (170-190 g, male) and Kunming mice (18-22 g, male) were obtained from Guangdong Medical Laboratory Animal Center
(License No: SCXK 2013-0002). All animals were acclimatized housing environment with $23 \pm 2^{\circ} \mathrm{C}$ and 12:12 h light-dark cycle for one week before the experiments. They were maintained on standard chow pellet and water ad libitum. All animal care and experimental procedures were approved by the Laboratory Animal Ethics Committee of Jinan University, and were in accordance with the National Institute of Health's Guide for the Care and Use of Laboratory Animals (the $7^{\text {th }}$ edition, USA).

\section{Cotton pellet induced rat granuloma test}

This test was performed according to the report of Santos and Rao [13]. SD rats were divided into six groups with ten each, including control group, dexamethasone group (DXM, i.p., $5 \mathrm{~mL} / \mathrm{kg}$ ), and four dosages of SQY treatment groups. The rats in SQY treatment groups were gavaged with $25.83 \mathrm{~mL} / \mathrm{kg}, 51.65 \mathrm{~mL} / \mathrm{kg}, 103.3 \mathrm{~mL} / \mathrm{kg}$ and 309.9 $\mathrm{mL} / \mathrm{kg}$ of SQY respectively according to human daily drinking volume $(10.33 \mathrm{~mL} / \mathrm{kg})$. The rats in the control group were treated with equivalent volume of purified water orally. The drugs were administrated once daily for 30 days. On the $23^{\text {th }}$ day of drug treatments, cotton pellets ( 23 $\pm 1 \mathrm{mg}$ ) were surgically implanted under the skin of the right groin of mice. Wounds were then sutured and animals were caged individually after recovery from anesthesia. On the $30^{\text {th }}$ day, rats were sacrificed and the pellets were removed together with the granuloma. Extraneous tissues were removed, and the pellet granulation tissues were then put in the plate and dried in oven with $60^{\circ} \mathrm{C}$ for 1 hour until the weight

Correspondence to: Rong-Rong $\mathrm{He}$ and $\mathrm{Yi}$-Fang $\mathrm{Li}$, Institute of Traditional Chinese Medicine and Natural Products, College of Pharmacy, Jinan University, Guangzhou 510632, P. R. China, Tel: 862085221559, E-mail: rongronghe@jnu.edu.cn and liyifang706@jnu.edu.cn

Key words: Shang Qing Yin (SQY), anti-inflammatory effect, rat granuloma test, rat paw edema test, mouse ear edema test

Received: December 02, 2016; Accepted: December 27, 2016; Published: January 04, 2017 
remained constant. Finally, the pellet granulation tissues were weight and expressed as the difference between the dry weight of the pellet granulation tissues and the corresponding weight of the original small cotton balls.

\section{Dextran-induced rat paw edema test}

This test was performed according to the report of Ribeiro NA et al. [14] Animal grouping and drug treatment were the same as those in cotton pellet induced rat granuloma test described above. On the $30^{\text {th }}$ day, acute inflammation was produced by subplantar injection of 0.1 $\mathrm{mL}$ of freshly prepared $1 \%(\mathrm{w} / \mathrm{v})$ dextran in normal saline into the right hind paws of rats. One hour after daily drug treatment, paw volume was measured plethysmometrically using a paw edema calcimeter at $0,1,2$, 4 and 6 hours after dextran injection. The same region was measured three times and the average was taken. The edema volumes were the difference between the paw volumes measured at different time and the paw volumes at zero hour. Calculate the paw edema rate each period of time. Paw edema rate was expressed as the paw edema volumes divide the paw volumes before the inflammatory agent effect.

\section{Dimethylbenzene-induced mouse ear edema test}

Mouse ear edema test was referenced to Zhang YB et al. and Li QZ et al. $[15,16]$. All mice were randomly divided into 7 groups $(n=12)$, also including control group, DXM group and SQY-treatment groups. The rats in control group were treated with equivalent volume of purified water orally. The rats in SQY-treatment groups were gavaged with $25.83,51.65,103.3,155.0$ and $309.9 \mathrm{~mL} / \mathrm{kg}$ SQY, respectively. In DXM group, mice were treated the same as described above. Each group should be dosed once daily for 30 days. On the $30^{\text {th }}$ day, one hour after daily drug treatment, topical application of dimethylbenzene (20 $\mu \mathrm{L} /$ ear) to the outer ears of right ear of mouse. The left ears without any application were as the control groups. Mice were sacrificed by cervical dislocation $30 \mathrm{~min}$ later then the ear biopsies of both ears were obtained with a punch (a diameter of $9 \mathrm{~mm}$ ) and weighed. The ear edema value was determined by subtracting the weight of the left ear from that of the right. Ear edema rate was expressed as the ear edema value divide the weight of the control ear slice.

\section{Statistical analysis}

The data were expressed as Mean \pm SEM and analyzed by student's t test using Graphpad Prism 6 software and $\mathrm{P}<0.05$ was considered statistically significant.

\section{Results}

\section{Results of cotton pellet induced rat granuloma test}

As shown in Figure 1, SQY at the dosages of 25.83 and $51.65 \mathrm{~mL} / \mathrm{kg}$ significantly reduced the granuloma weight induced by cotton pellet in rats $(\mathrm{P}<0.01)$. Nevertheless, comparing with control group, SQY $(103.3$ and $309.9 \mathrm{~mL} / \mathrm{kg}$ ) treatment didn't strikingly influence the granuloma weights (338.6 \pm 23.09 in control group vs. $280.8 \pm 27.24$ in $103.3 \mathrm{~mL} /$ $\mathrm{kg}$ SQY group and $270.7 \pm 27.2$ in $309.9 \mathrm{~mL} / \mathrm{kg}$ SQY group).

\section{Results of dextran-induced rat paw edema test}

In the Figure 2A, SQY treatment had no obvious effect on the paw edema rate at $1 \mathrm{~h}$ after dextran-administration. However, the SQYtreatment groups had significant differences compared with the control group at $2 \mathrm{~h}, 4 \mathrm{~h}$ and $6 \mathrm{~h}$ after dextran injection (Figures 2B-2D). This data indicated that SQY exerted anti-inflammation effects in dextraninduced rat paw edema test, but the initial effective time of the anti-

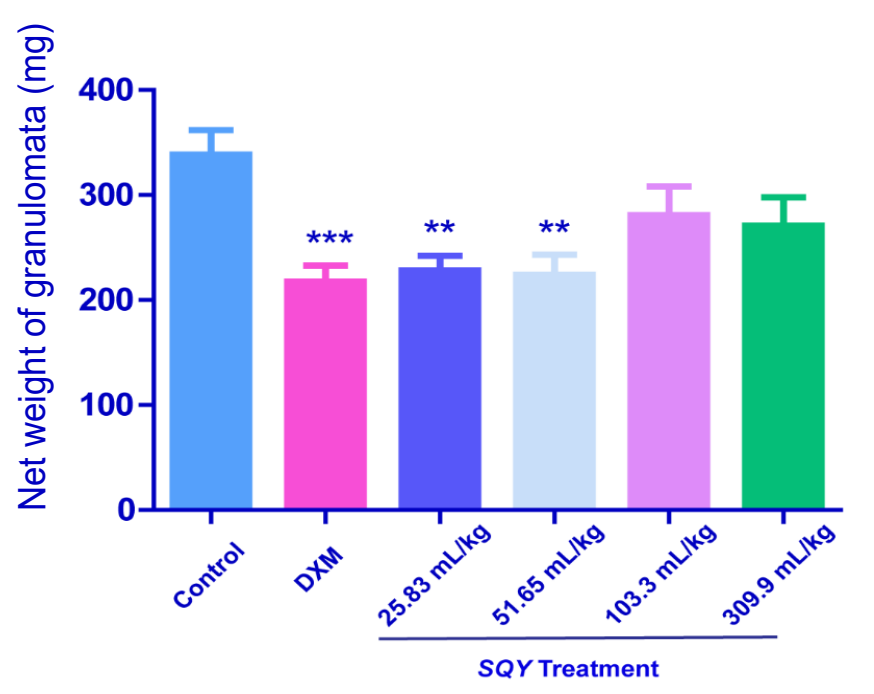

Figure 1. Anti-inflammation effects ofSQY incottonpelletinducedrat granuloma test [The pellet granulation tissues were weight and the net weight of granulomata of different groups (control, DXM, $25.83 \mathrm{~mL} / \mathrm{kg}, 51.65 \mathrm{~mL} / \mathrm{kg}, 103.3 \mathrm{~mL} / \mathrm{kg}$ and $309.9 \mathrm{~mL} / \mathrm{kg}$ of SQY treatment) were expressed as the difference between the dry weight of the pellet granulation tissues and the corresponding weight of the original small cotton balls. Compared with control group, $* * \mathrm{P}<0.01, * * * \mathrm{P}<0.001]$.

inflammatory effect of SQY was slightly slowly when compared with DXM.

\section{Results of dimethylbenzene-induced mouse ear edema test}

As shown in Figure 3, SQY at the dosages of 51.65, 103.3, 155.0 and $309.9 \mathrm{~mL} / \mathrm{kg}$ significantly reduced ear edema rate caused by dimethylbenzene, although SQY had no significant influence at the dosage of $25.83 \mathrm{~mL} / \mathrm{kg}$. These results demonstrated an antiinflammatory action on dimethylbenzene-induced ear edema at higher dosages.

\section{Discussion}

In the present study, we utilized three in vivo models, including cotton pellet induced rat granuloma test and dextran-induced rat paw edema test, as well as dimethylbenzene-induced mouse ear edema test, to examine the anti-inflammatory effects of SQY. The cotton pelletinduced granuloma formation is a typical symptom of a chronic inflammation reaction. The process has been broadly employed to evaluate the exudative and proliferative components of chronic inflammation, as the dried weight of the cotton pellet correlates well with the amount of granulomatous tissues [17]. Thus, we firstly employed the cotton pellet induced rat granuloma test to investigate the anti-inflammatory effects of SQY and a significant reduction in the granuloma weights at the dosages of $51.65,103.3 \mathrm{~mL} / \mathrm{kg}$, and the efficacy was closed to DXM treatment. Lo et al. and Calixto [18,19] reported that edema produced by subplantar injection of dextran in animals is characterized by a rapid increase in the paw edema and spontaneous decrease after $30 \mathrm{~min}$, with histamine and serotonin being the main mediators. In our study, a significant anti-inflammatory effect of SQY were also observed in the dextran-induced rat paw edema test at the dosages of 25.83 and $51.65 \mathrm{~mL} / \mathrm{kg}$, other than at higher dosages 103.3 and $309.9 \mathrm{~mL} / \mathrm{kg}$. We speculate that SQY may cause allergy at high dosages, due to Frangipani in SQY have been reported to induce such adverse effects [20]. In order to further evaluate the anti-inflammatory 
A.

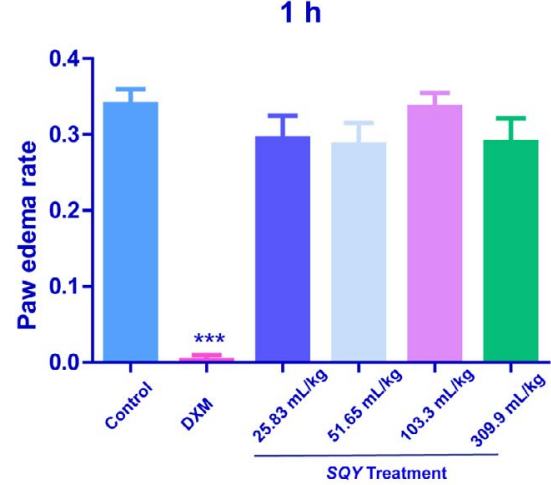

C.

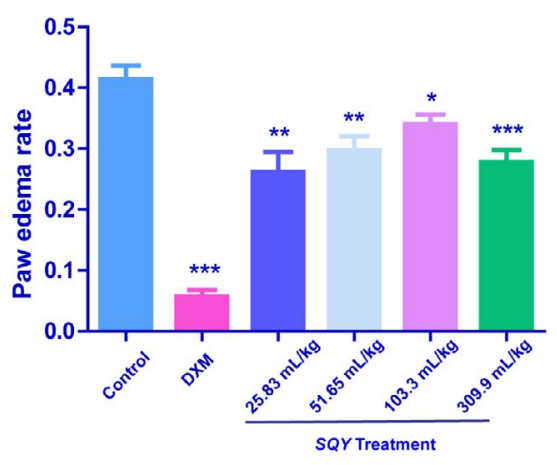

E.

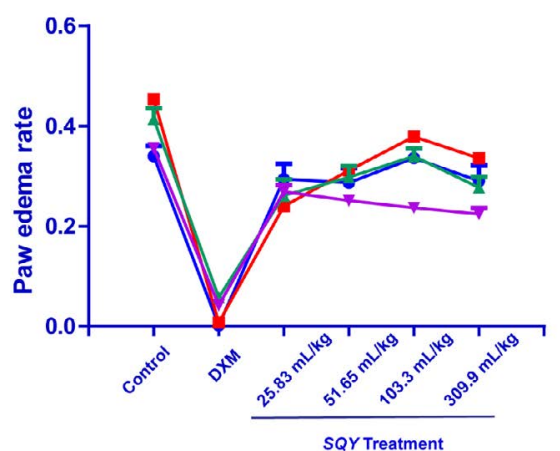

B. $2 \mathrm{~h}$

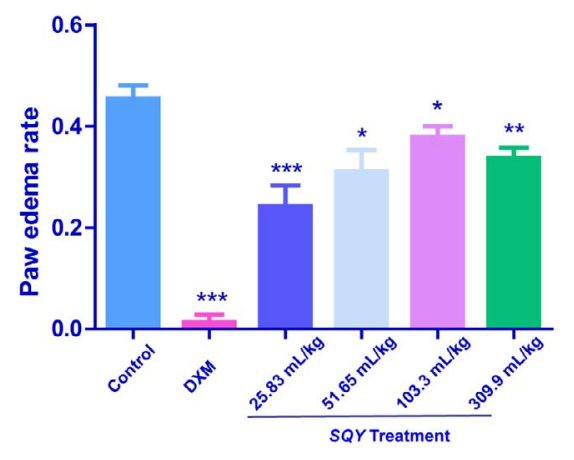

D.

$6 \mathrm{~h}$

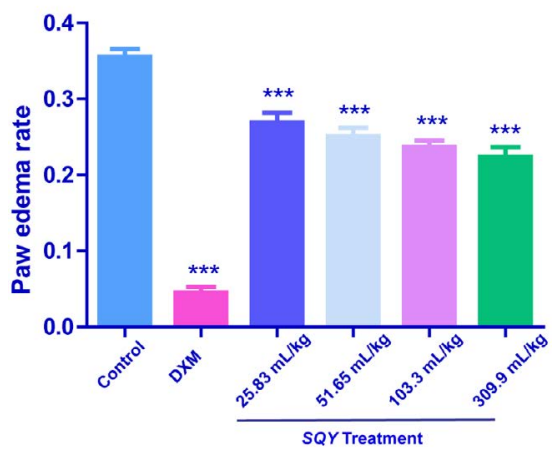

Figure 2. Anti-inflammation effects of SQY in dextran-induced rat paw edema test [The paw edema volumes were the paw volumes' difference measured between at different time and at zero hour by a paw edemacalcimeter. Paw edema rate was expressedasthepawedemavolumesdividethepawvolumesbeforethe inflammatory agent effect . Paw edema rates were determined at $1 \mathrm{~h}(\mathrm{~A}), 2 \mathrm{~h}(\mathrm{~B}), 4 \mathrm{~h}(\mathrm{C}), 6 \mathrm{~h}(\mathrm{D})$, and the time point changes is indicated in (E). Compared with control group, $\left.{ }^{*} \mathrm{P}<0.05,{ }^{*} * \mathrm{P}<0.01,{ }^{*} * * \mathrm{P}<0.001\right]$

activity of the extract, the dimethylbenzene-induced ear edema test was also employed. In the process of inflammation, activated neutrophils release mediators such as platelet-activating factor and lysozyme, which can lead to vasodilatation and increase vascular permeability [21]. In the present study, it was also shown that middle concentration SQY significantly inhibited ear edema of mice. In the dimethylbenzeneinduced mouse ear edema test, SQY had obvious anti-inflammatory effects at the dosages of 51.65, 155.0, 309.9 and $103.3 \mathrm{~mL} / \mathrm{kg}$ while $25.83 \mathrm{~mL} / \mathrm{kg}$ showed no significant effect. By analyzing the results from above tests, it can be seen that the effective dosages of SQY in different tests were distinct. It may be due to the species differences and model distinction.
SQY is made from Fructus Chebulae, Patchouli and Liquorice, which have been reported to possess anti-inflammatory effects. Lee et al. demonstrated Fructus Chebulae inhibited the production of inflammatory mediators and reduced nitric oxide (NO) production, inducible nitric oxide synthase (iNOS), and cyclooxygenase-2 (COX2) expression in RAW 264.7 [22]. Yoon et al. reported that the aqueous extract of Patchouli was proved to have anti-allergic and antiinflammatory effects by reduced intracellular calcium levels and the activation of NF- $\mathrm{kB}$ and p38 MAPK. [23]. What's more, Menegazzi et al. proved that glycyrrhizin, a major active constituent of Liquorice root, had anti-inflammatory and anti-viral activities [24]. Thus, it can be inferred that the effects of SQY on inflammation might be associated 


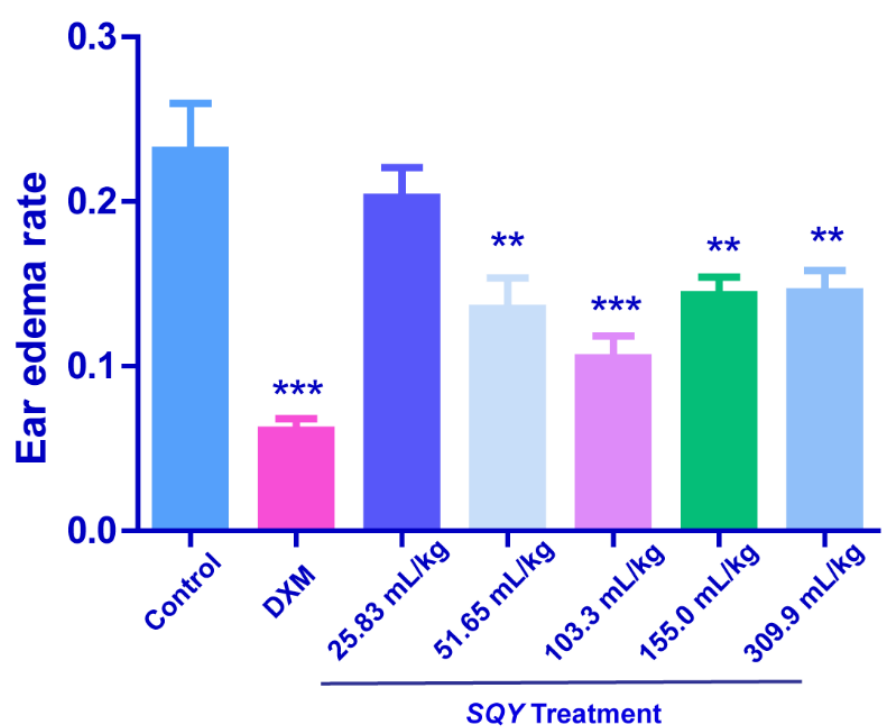

Figure 3. Anti-inflammation effects of SQY in dimethylbenzene-induced mouse ear edema test [The ear edema value was determined by subtracting the weight of the left control ear from that of the right that applied with dimethylbenene $(20 \mu \mathrm{L} / \mathrm{ear})$ to the outer ear. Ear edema rate was expressed as the ear edema value divide the weight of the control ear slice. Compared with control group, $* * \mathrm{P}<0.01, * * * \mathrm{P}<0.001]$.

with these components. Nevertheless, what's the exact mechanism needs more investigation in the future study.

\section{References}

1. Coussens LM, Werb Z (2002) Inflammation and cancer. Nature 420: 860-867. [Crossref]

2. Shu XS, Gao ZH, Yang XL (2006) Anti-inflammatory and anti-nociceptive activities of Smilax china L. aqueous extract. J Ethnopharmacol 103: 327-332. [Crossref]

3. Ballabh B, Chaurasia OP, Ahmed Z, Singh SB (2008) Traditional medicinal plants of cold desert Ladakh-used against kidney and urinary disorders. J Ethnopharmacol 118 : 331-339. [Crossref]

4. Lee HS, Won NH, Kim KH, Lee H, Jun W, et al. (2005) Antioxidant effects of aqueous extract of Terminalia chebula in vivo and in vitro. Biol Pharm Bull 28: 1639-1644. [Crossref]

5. Saleem A, Husheem M, Härkönen P, Pihlaja K (2002) Inhibition of cancer cell growth by crude extract and the phenolics of Terminalia chebula retz. fruit. J Ethnopharmacol 81: 327-336. [Crossref]

6. Chang CL, Lin CS (2012) Phytochemical Composition, Antioxidant Activity, and Neuroprotective Effect of Terminalia chebula Retzius Extracts. Evid-Based Compl Alt 2012:1-7

7. Pansard Y, De Brux JL, Cohen-Solal A, Steg G, Himbert D, et al. (1987) [Hydatid cyst of the right heart and post-embolic pulmonary hypertension]. Arch Mal Coeur Vaiss 80: 667-669. [Crossref]
8. Huang YN, Zhao DD, Gao B, Zhong K, Zhu RX, et al. (2012) Anti-hyperglycemic effect of chebulagic acid from the fruits of Terminalia chebula Retz. Int J Mol Sci 13 . 6320-6333. [Crossref]

9. Kim JH, Koo YC, Hong CO, Yang SY, Jun W, et al. (2012) Mutagenicity and oral toxicity studies of Terminalia chebula. Phytother Res 26: 39-47. [Crossref]

10. Sharma P, Prakash T, Kotresha D, Ansari MA, Sahrm UR, et al. (2011) Antiulcerogenic activity of Terminalia chebula fruit in experimentally induced ulcer in rats. Pharm Biol 49: 262-268. [Crossref]

11. Lee HS, Jung SH, Yun BS, Lee KW (2007) Isolation of chebulic acid from Terminalia chebula Retz. and its antioxidant effect in isolated rat hepatocytes. Arch Toxicol 81: 211-218. [Crossref]

12. Suchalatha S, Shyamala Devi CS (2004) Protective effect of Terminalia chebula against experimental myocardial injury induced by isoproterenol. Indian J Exp Biol 42: 174-8.

13. Santos FA, Rao VS (2000) Antiinflammatory and antinociceptive effects of 1,8-cineole a terpenoid oxide present in many plant essential oils. Phytother Res 14:240-4.

14. de Araújo IW, Rodrigues JA, Quinderé AL, Silva JF, Maciel GF, et al. (2016) Analgesic and anti-inflammatory actions on bradykinin route of a polysulfated fraction from alga Ulva lactuca. Int J Biol Macromol 92: 820-830. [Crossref]

15. Zhang YB, Shu ZH, Yin L, Ma L, Wang XF, Fu XY (2015) Anti-inflammatory and antinociceptive activities of non-alkaloids fractions from Aconitum flavum in vivo. Rev Bras Farmacogn 25:47-52.

16. Li Q, Yang S, Yang S, Xin F, Wang M (2015) Anti-inflammatory activity of phlomisoside $\mathrm{F}$ isolated from Phlomis younghusbandii Mukerjee. Int Immunopharmacol 28: 724 730. [Crossref]

17. Chen XB, Su HW, Liu HX, Yin X, He F, et al. (2016) Anti-inflammatory and analgesic effects of Bi-yuan-ling granules. J Huazhong Univ Sci Technolog Med Sci 36: 456-462. [Crossref]

18. Lo TN, Almeida AP, Beaven MA (1982) Dextran and carrageenan evoke different inflammatory responses in rat with respect to composition of infiltrates and effect of indomethacin. J Pharmacol Exp Ther 221: 261-7.

19. Calixto JB (2005) Twenty-five years of research on medicinal plants in Latin America a personal view. $J$ Ethnopharmacol 100: 131-134. [Crossref]

20. Warsito R, Djayus Y, Harahap ZA (2015) Uji Toksisitas Akut Ekstrak Daun Kamboja (Plumiera rubra L.) pada Ikan Nila Merah (Oreochromis niloticus) Acute Toxicity Test Extract Frangipani Leaves (Plumiera rubra L.) on the Red Tilapia (Oreochromis niloticus). AQUACOASTMARINE 8: 12.

21. Saeed MK, Deng Y, Dai R, Li W, Yu Y, et al. (2010) Appraisal of antinociceptive and anti-inflammatory potential of extract and fractions from the leaves of Torreya grandis Fort Ex. Lindl. J Ethnopharmacol 127: 414-418. [Crossref]

22. Lee HH, Paudel KR, Kim DW (2015) Terminalia chebula fructus inhibits migration andproliferation of vascular smooth muscle cells and production of inflammatory mediators in RAW 264.7. Evidence-Based Complementary and Alternative Medicine 2015.

23. Yoon SC, Je IG, Cui X, Park HR, Khang D, et al. (2016) Anti-allergic and antiinflammatory effects of aqueous extract of Pogostemon cablin. Int J Mol Med 37: 217 224. [Crossref]

24. Menegazzi M, Di Paola R, Mazzon E, Genovese T, Crisafulli C, et al (2008) Glycyrrhizin attenuates the development of carrageenan-induced lung injury in mice. Pharmacol Res 58: 22-31. [Crossref]

Copyright: (C2017 Tu LF. This is an open-access article distributed under the terms of the Creative Commons Attribution License, which permits unrestricted use, distribution, and reproduction in any medium, provided the original author and source are credited. 